\title{
Referral of Patients to Specialists: Factors Affecting Choice of Specialist by Primary Care Physicians
}

\author{
Kraig S. Kinchen, $M D, M S c^{1}$ \\ Lisa A. Cooper, $M D, M P H^{2,3,4}$ \\ David Levine, $M D, S c D^{3,4}$ \\ Nae Yub Wang, PbD ${ }^{2}$ \\ Neil R. Powe, MD, MPH, MBA $A^{2,3,4}$ \\ 'Robert Wood Johnson Clinical Scholars \\ Program, The Johns Hopkins University \\ School of Medicine, Baltimore, Md
}

${ }^{2}$ Welch Center for Prevention, Epidemiology and Clinical Research, The Johns Hopkins

University, Baltimore, Md

${ }^{3}$ Department of Medicine, The Johns Hopkins University School of Medicine, Baltimore, Md

${ }^{4}$ Department of Health Policy and Management, Johns Hopkins Bloomberg School of Public Health, Baltimore, Md

Conflicts of interest: none reported

\section{CORRESPONDING AUTHOR}

Neil R. Powe, MD, MPH, MBA

Welch Center for Prevention, Epidemiology, and Clinical Research The Johns Hopkins University 2024 East Monument St, Suite 2-600 Baltimore, MD 21205-2223 npowe@jhmi.edu

\begin{abstract}
BACKGROUND We wanted to determine the importance of factors in primary care physicians' choice of specialist when referring patients and to compare importance ratings by physicians' race and sex.

METHODS Using a cross-sectional study design, we surveyed a stratified national sample of 1,252 primary care physicians serving adults to include equal numbers of black women, white women, black men, and white men. We assessed the percentage of physicians rating each of 17 items to be of major importance in choosing a specialist and compared importance ratings by physicians' race and sex.
\end{abstract}

RESULTS The response rate was $59.1 \%$. Medical skill, appointment timeliness, insurance coverage, previous experience with the specialist, quality of specialist communication, specialist efforts to return patient to primary physician for care, and the likelihood of good patient-specialist rapport were of major importance to most respondents. Compared with black physicians, white physicians were more likely to rate previous experience with the specialist ( $65 \%$ vs $55 \%, P=.05)$ and board certification ( $41 \%$ vs $29 \%, P<.05$ ) to be of major importance. White physicians were somewhat less likely than black physicians ( $17 \%$ vs $26 \%, P=.06)$ to rate patient convenience to be of major importance. Compared with male physicians, female physicians were more likely to rate the patient's insurance status to be of major importance ( $60 \%$ vs $44 \%, P<.01)$.

CONCLUSIONS Primary care physicians serving adults consider several factors to be of major importance when choosing a specialist. The importance of patient convenience, previous experience with the specialist, specialist board certification, and insurance coverage accepted by specialist varied by physicians' race and sex. A better understanding of factors important to a diverse physician workforce may help to improve the referral process.

Ann Fam Med 2004;245-252. DOI: 10.1370/afm.68.

\section{INTRODUCTION}

$\mathrm{R}$ eferral of patients from primary care physicians to specialists may affect the process of patient evaluation, treatment, ${ }^{1}$ and continuity of care ${ }^{2}$ and can affect clinical outcomes ${ }^{3}$ and costs. ${ }^{4-6}$ Approximately $4.5 \%$ of all patient visits in the United States result in referral, ${ }^{7}$ and physicians receive up to $45 \%$ of new patients by referral. ${ }^{8}$ For the primary care physician, the referral decision involves not only whether the patient needs to be referred to a specialist, but also which specialist should be chosen to see the patient. The latter question has taken on increasing importance as the growth in the number and types of health plan arrangements has altered traditional referral relationships between primary care physicians and specialists. Plans may restrict the specialists that are able to care for members and may place primary care physicians in the role of gatekeepers. ${ }^{9}, 10$ Thus, primary care physicians accustomed to referring their 
patients to particular specialists may have to select specialists with whom they are less familiar. ${ }^{11}$

Early studies have examined aspects of the process of choosing specialists for patient referral. ${ }^{12-17}$ These studies, however, were limited in geographic representation and in the diversity of physicians included, and may not reflect the current race and sex composition of the physician workforce and the environment in which many physicians practice. The objective of this study was to determine the factors (specialists' characteristics, practice characteristics, interaction between patient and specialist, and interaction between primary care physician and specialist) that primary care physicians serving adults consider most important when selecting specialists.

Additionally, in light of an increasingly diverse patient population and related efforts to diversify the physician workforce, ${ }^{18}$ we sought to determine whether the perceived importance of factors in the referral decision was consistent across primary care physician race and sex. We examined the potential impact of race and sex for 2 reasons. First, recent work shows that several aspects of physician behavior and patient ratings of care vary by physician race and sex. ${ }^{19,20}$ Minority physicians, for example, often serve a sicker and more socioeconomically vulnerable patient population ${ }^{21-24}$ and encounter more difficulties obtaining hospital admissions and referrals for their patients. ${ }^{25}$ Would potential concerns about the importance of insurance status affect the referral decisions of black physicians and white physicians differently? Previous studies show that female physicians engage in more communication considered to be patient centered. ${ }^{26}$ Would female physicians rate factors related to patient-specialist interaction as more important than male physicians?

Second, in an earlier study of black physicians, ${ }^{27}$ respondents reported a perception of discrimination against black physicians by white physicians in the referral process. In addition to studies that might explore further the potential persistence and rationale for this perception among some black physicians, our study may shed some light on this issue by determining whether white and black primary care physicians value the same qualities when choosing a specialist for patient referral.

The interface between primary care physicians and specialist physicians has been identified as an important area for research. ${ }^{28}$ In the current practice environment, primary care physicians and specialists have reported dissatisfaction with aspects of the referral process. ${ }^{29}$ Whereas ideally referrals facilitate improved patient care, Lanier and Clancy ${ }^{28}$ note that referrals "often result in confusion, discordant or ambiguous provider and patient expectations, and redundant or inadequate care." For specialists and administrators of health care systems and institutions, a better understanding of the importance of various factors to primary care physicians when choosing a specialist, as well as the potential impact of physician race and sex, could help to clarify primary care physicians' expectations of specialists and improve the referral process.

\section{METHODS}

\section{Study Design}

We conducted a national cross-sectional survey of primary care physicians who see adult patients. The sample was drawn from the American Medical Association Physicians Professional Data, which is a database of US physicians that includes physician sex, specialty, age, race, and location. We conducted stratified random sampling of practicing physicians to obtain equal numbers of black female, black male, white female and white male physicians. A sample size of 1,252 was chosen to obtain 500 responses, assuming a $50 \%$ response rate and the possible exclusion of $20 \%$ of the sample. Physicians were excluded if they were no longer serving as a primary care physician for adults or if the questionnaire could not be delivered because of an incorrect address The protocol was approved by the institutional review board at Johns Hopkins Medical Institutions.

\section{Survey Instrument}

The mailed survey instrument included a 17 -item questionnaire in which respondents were asked about the importance of various factors when choosing a medical specialist to whom to refer a patient. Items were derived from a review of the literature. ${ }^{12,15,17}$ and included variables related to qualities of the specialist, characteristics of the specialist's practice, interaction between the primary care physician and the specialist, and interaction between the specialist and the patient. The respondents rated the importance of each item on a 4-point Likert scale of no, mild, moderate, and major importance.

Additional questionnaire data included the respondent's practice type, specialty, age, sex, race, board-certification status, medical school, years in practice, and location of practice, as well as the reported frequency that respondents knew the names of the specialists to whom they referred patients. Respondents estimated the percentage of their patients seen during a typical week of practice for which they make an initial referral to a specialist. The questionnaire was pilot-tested on primary care physicians at our institution.

\section{Data Collection}

From May to October 2000, physicians received up to 3 survey mailings, a reminder postcard, a reminder telephone call from an investigator $(\mathrm{KK})$, and a faxed survey instrument. Unique questionnaire identification numbers 
were used for tracking purposes, and physician identity remained confidential. Physicians were informed of the option to indicate a refusal to participate in the study by checking the appropriate questionnaire box.

\section{Data Analysis}

We used chi-square tests to compare characteristics of the respondents by race and by sex. We compared characteristics of respondents and nonrespondents. For each factor potentially considered in the choice of specialist, we used chi-square tests to compare, by race and by sex, the percentage of respondents who stated that a factor was of major importance.

We then conducted separate multivariate logistic regression analyses using a rating of major importance as the outcome of interest. In the first set of models, our main independent variable was self-reported race (white vs black). To control for the possibility of confounding, we included covariates that were associated $(P<.10)$ with race as well as with at least 1 of the 14 outcomes of interest. For the second set of models for which the main independent variable was respondent sex, a corresponding standard was used for selection of covariates. Potential covariates included practice type, age-group, board-certification status, international vs US medical school graduate status, specialty, region, practice location, and whether the respondent almost always knows the name of the specialist when they refer patients. Race and sex were included in all models. To assess the potential interaction between physician race and sex, we included an interaction term in each model and removed the interaction term from the model if it was not significant. Adjusted percentages were calculated based on the adjusted odds ratios derived from logistic regression ${ }^{30}$ and the relevant unadjusted frequencies of the reference groups (white physicians in comparisons of race and male physicians in comparisons of sex) in each analysis. Analyses were performed using Stata (StataCorp LP, version 7.0, College Station, Tex).

The funding source had no role in study design, analysis, or writing of the manuscript. The authors had full access to the data in this study.

\section{RESULTS}

Response Rate and Respondent Characteristics Of the 1,252 physicians sampled, 143 (11.4\%) were no longer practicing primary care physicians, 55 (4.4\%) had incorrect addresses, 46 (3.7\%) refused to participate, and 385 (30.8\%) did not respond. The overall response rate was $59.1 \%(623 / 1,054)$. For eligible physicians (excluding incorrect addresses and physicians no longer practicing primary care), the respondents were more likely than nonrespondents to be white $(P<.01$; $53 \%$ vs $42 \%)$, but the groups were not significantly different by sex, specialty, mean age, or region of the country. Of the 623 returned questionnaires, 8 were excluded because less than one half of the items had been completed. Approximately $29 \%$ of the returned questionnaires were received after the first mailing, another $32 \%$ in response to a reminder postcard and second mailing, and $39 \%$ in response to a faxed survey instrument and reminder telephone call.

Female physicians make up $53.2 \%$ of the sample. As we were interested in comparisons between white and black physicians $(\mathrm{n}=558)$, we excluded from this analysis respondents who did not report race $(n=24)$ or reported a race other than white or black $(n=33)$.

Fewer than one half of physicians reported referring more than $10 \%$ of their patients in a typical week of practice (Figure 1). With regard to respondent characteristics, black physicians (54\%) were much more likely than white physicians $(29 \%)$ to practice in urban settings (Table 1).

\section{Factors Important in Choosing a Specialist}

A total of $88 \%$ of respondents considered the medical skill of the specialist to be of major importance (Table 2). The timeliness of the patient's appointment and acceptance of the patient's insurance coverage were considered to be of major importance by $55 \%$ and $50 \%$ of respondents, respectively. With regard to factors involving interaction between primary care physicians and specialists, 3 items were of major importance to most respondents: previous experience with the specialist (59\%), quality of specialist communication to the primary care physician (53\%), and the specialist's efforts to return the patient to the primary care physician for primary care (51\%).

After adjusting for potential confounders, there were few significant differences between black and white physicians (Table 3). Board certification remained less

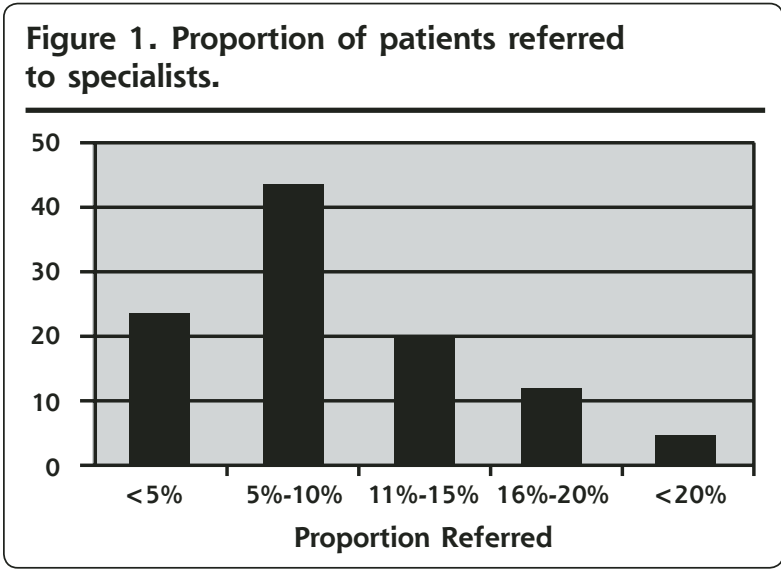


Table 1. Characteristics of Primary Care Physician Respondents: Overall and by Race and Sex

\begin{tabular}{|c|c|c|c|c|c|c|}
\hline & $\begin{array}{c}\text { White } \\
\mathrm{n}=316\end{array}$ & $\begin{array}{c}\text { Black } \\
\mathrm{n}=242\end{array}$ & & $\begin{array}{c}\text { Male } \\
n=262\end{array}$ & $\begin{array}{c}\text { Female } \\
n=296\end{array}$ & \\
\hline Characteristics & n (\%) & n (\%) & $P$ Value & n (\%) & n (\%) & $P$ Value \\
\hline Age & & & $<.01$ & & & $<.01$ \\
\hline$<40$ years & $93(29.7)$ & $99(42.3)$ & & $58(22.7)$ & $134(46.1)$ & \\
\hline $40-49$ years & $125(39.9)$ & $97(41.5)$ & & $98(38.3)$ & $124(42.6)$ & \\
\hline$>49$ years & $95(30.4)$ & $38(16.2)$ & & $100(39.1)$ & $33(11.3)$ & \\
\hline Sex, female & $163(51.6)$ & $133(55.0)$ & .43 & --- & --- & NA \\
\hline Race, black & --- & --- & NA & $109(41.6)$ & $133(44.9)$ & .43 \\
\hline Board certified & $285(90.5)$ & $190(79.2)$ & $<.01$ & $216(82.8)$ & $259(88.1)$ & .07 \\
\hline International medical graduate & $20(6.3)$ & $39(16.4)$ & $<.01$ & $36(13.8)$ & $23(7.9)$ & .02 \\
\hline Location & & & $<.01$ & & & .35 \\
\hline Rural & $95(30.0)$ & $35(14.6)$ & & $67(25.8)$ & $63(21.4)$ & \\
\hline Urban & $92(29.1)$ & $130(54.4)$ & & $103(39.6)$ & $119(40.3)$ & \\
\hline Suburban & $127(40.2)$ & $74(40.0)$ & & $90(34.6)$ & $111(37.6)$ & \\
\hline Other & $2(0.63)$ & $0(0.0)$ & & $0(0.0)$ & $2(0.68)$ & \\
\hline Practice setting & & & $<.01$ & & & $<.01$ \\
\hline Hospital clinic & $38(12.7)$ & $28(11.8)$ & & $27(10.8)$ & $39(13.6)$ & \\
\hline Staff/group HMO & $7(2.3)$ & $26(11.0)$ & & $10(4.0)$ & $23(8.0)$ & \\
\hline Private group & $155(51.7)$ & $80(33.8)$ & & $110(43.8)$ & $125(43.7)$ & \\
\hline Solo & $74(24.7)$ & $69(29.1)$ & & $87(34.7)$ & $56(19.6)$ & \\
\hline Other practice & $26(8.7)$ & $34(14.4)$ & & $17(6.8)$ & $43(15.0)$ & \\
\hline Specialty & & & .22 & & & .02 \\
\hline Family practice & $151(50.3)$ & $100(45.5)$ & & $103(43.5)$ & $148(52.3)$ & \\
\hline Internal medicine & $120(40.0)$ & $106(48.2)$ & & $107(45.2)$ & $119(42.1)$ & \\
\hline FP/IM with specialty & $17(5.7)$ & $9(4.1)$ & & $19(8.0)$ & $7(2.5)$ & \\
\hline Other & $12(4.0)$ & $5(2.3)$ & & $8(3.4)$ & $9(3.2)$ & \\
\hline Region & & & $<.01$ & & & .03 \\
\hline South & $82(26.0)$ & $106(43.8)$ & & $104(39.7)$ & $84(28.4)$ & \\
\hline Northeast & $76(24.1)$ & $54(22.3)$ & & $60(22.9)$ & $70(23.7)$ & \\
\hline Midwest & $92(29.1)$ & $49(20.3)$ & & $58(22.1)$ & $83(28.0)$ & \\
\hline West & $66(20.9)$ & $33(13.6)$ & & $40(15.3)$ & 59 (19.9) & \\
\hline $\begin{array}{l}\text { Almost always knows name of } \\
\text { specialist referring to }\end{array}$ & $274(86.7)$ & $172(71.1)$ & $<.01$ & $212(80.9)$ & $234(79.1)$ & .35 \\
\hline
\end{tabular}

$\mathrm{NA}=$ not applicable; $\mathrm{FP}=$ family practice; IM = internal medicine; $\mathrm{HMO}=$ health maintenance organization.

Note: numbers for missing values by characteristics were: age (11); board certified (3), international medical graduate (4); location (3); practice setting (21); specialty (38).

important for black respondents than white respondents ( $29 \%$ vs $41 \%, P<.05)$, as did the primary care physician's previous experience with the specialist $(55 \%$ vs $65 \%, P$ $<.05$ ). The greater importance assigned by black physicians than white physicians to patient convenience was of borderline statistical significance ( $26 \%$ vs $17 \%, P=.06)$.

In adjusted analyses (Table 4 ), female physicians were more likely than male physicians to rate insurance coverage of major importance $(60 \%$ vs $44 \%, P<.05)$ and less likely to rate of major importance the return of the patient by the specialist to the primary care physician for further management ( $46 \%$ vs $59 \%, P<.05$ ). Because the interaction term for race and sex was not significant $(P<.05)$ in the regression models, it was excluded from the final models.

\section{DISCUSSION}

Primary care physicians frequently have to make choices about the specialists to whom their patients should be referred. The assertion that the choice of specialists is important is based on the assumption that different specialists may be able to provide different quality of care. Changes in the health care system in some cases have altered traditional referral relationships. Thus, determinations of which specialist might provide the best quality of care often must be made with less information about and less familiarity with specialists.

To our knowledge, we report the first national study of family physicians' and internists' perceptions of the importance of specialists' characteristics, practice characteristics, interactions between primary care 


\begin{tabular}{|c|c|c|c|c|c|}
\hline \multirow[b]{2}{*}{ Factor } & \multicolumn{5}{|c|}{ Importance Rating, Percent of Respondents } \\
\hline & No. & No. & Mild & Moderate & Major \\
\hline Medical skill & 545 & 0.0 & 0.2 & 12.3 & 87.5 \\
\hline $\begin{array}{l}\text { Previous experience with } \\
\text { specialist }\end{array}$ & 552 & 0.2 & 6.2 & 34.4 & 59.2 \\
\hline Appointment timeliness & 549 & 0.2 & 3.6 & 40.8 & 55.4 \\
\hline Quality of communication & 552 & 0.0 & 4.9 & 42.6 & 52.5 \\
\hline $\begin{array}{l}\text { Likelihood of good patient- } \\
\text { physician rapport }\end{array}$ & 553 & 0.7 & 5.4 & 42.5 & 51.4 \\
\hline $\begin{array}{l}\text { Specialist returns to primary } \\
\text { physician }\end{array}$ & 550 & 2.0 & 12.0 & 34.9 & 51.1 \\
\hline Insurance coverage & 550 & 8.2 & 15.5 & 26.7 & 49.6 \\
\hline $\begin{array}{l}\text { Patient preference for } \\
\text { particular specialist }\end{array}$ & 553 & 0.9 & 10.0 & 48.3 & 40.9 \\
\hline $\begin{array}{l}\text { Primary care physician } \\
\text { relationship with specialist }\end{array}$ & 552 & 3.6 & 15.8 & 44.8 & 35.9 \\
\hline Board certification & 549 & 5.8 & 20.2 & 40.1 & 33.9 \\
\hline Patient convenience & 551 & 1.1 & 19.1 & 56.1 & 23.8 \\
\hline $\begin{array}{l}\text { Attitudes of colleagues toward } \\
\text { specialist }\end{array}$ & 553 & 4.7 & 34.2 & 46.7 & 14.5 \\
\hline Hospital affiliation & 551 & 10.9 & 33.6 & 41.9 & 13.6 \\
\hline Office location & 551 & 4.9 & 34.7 & 51.0 & 9.4 \\
\hline $\begin{array}{l}\text { Specialist refers patients to } \\
\text { primary physician }\end{array}$ & 552 & 37.3 & 42.0 & 16.5 & 4.2 \\
\hline Medical school & 553 & 47.0 & 43.8 & 8.9 & 0.4 \\
\hline Fellowship training institution & 552 & 40.4 & 44.4 & 15.0 & 0.2 \\
\hline
\end{tabular}

physicians and specialist and interactions between patients and specialists in their decisions to refer patients. Appropriately, medical skill of the specialist was of greatest importance, however, other important factors included the primary care physician's previous experience with the specialist, the quality of specialist's communication, the specialist's efforts to return the patient to the primary care physician for primary care, and the likelihood of a good rapport between patient and specialist. Factors often included in referral databases, such as specialist's hospital affiliation, institution of fellowship training, and institution of undergraduate medical training, were much less important.

Although medical skill was of greatest importance, how physicians make the determination of the specialist's skill is not

Table 3. Percentage of Black and White Primary Care Physicians Who Rated Factors of Major Importance in Choosing a Specialist

\begin{tabular}{|c|c|c|c|c|c|c|c|}
\hline \multirow[b]{2}{*}{ Factors } & \multicolumn{4}{|c|}{ Unadjusted Percent } & \multicolumn{3}{|c|}{ Adjusted Percent* $(95 \% \mathrm{Cl})$} \\
\hline & No. & White & Black & $P$ Value & No. & Black & $P$ Value \\
\hline \multicolumn{8}{|l|}{ Specialist characteristics } \\
\hline Medical skill & 545 & 90.3 & 83.9 & .03 & 510 & $88(79-93)$ & .40 \\
\hline Board certification & 549 & 40.5 & 25.4 & $>.01$ & 514 & $29(20-39)$ & .03 \\
\hline \multicolumn{8}{|l|}{ Practice characteristics } \\
\hline Appointment timeliness & 549 & 51.5 & 60.4 & .04 & 513 & $54(44-64)$ & .63 \\
\hline Insurance coverage & 550 & 49.8 & 49.4 & .92 & 514 & $51(41-62)$ & .80 \\
\hline Hospital affiliation & 551 & 13.9 & 13.3 & .84 & 515 & $14(8-23)$ & .98 \\
\hline \multicolumn{8}{|l|}{ Primary care physician-specialist interaction } \\
\hline $\begin{array}{l}\text { Primary care physician previous experience } \\
\text { with specialist }\end{array}$ & 552 & 65.0 & 51.9 & $<.01$ & 516 & $55(44-65)$ & .05 \\
\hline $\begin{array}{l}\text { Specialist returns patient to primary care } \\
\text { physician }\end{array}$ & 550 & 47.3 & 56.0 & .04 & 515 & $58(47-68)$ & .05 \\
\hline Quality of communication & 552 & 48.7 & 57.4 & .04 & 516 & $53(43-63)$ & .40 \\
\hline $\begin{array}{l}\text { Primary care physician relationship with } \\
\text { specialist }\end{array}$ & 552 & 35.8 & 36.0 & .97 & 516 & $35(26-45)$ & .84 \\
\hline Attitudes of colleagues toward the specialist & 553 & 16.4 & 12.0 & .14 & 517 & $13(8-21)$ & .37 \\
\hline \multicolumn{8}{|l|}{ Patient-specialist interaction } \\
\hline Likelihood of good patient-physician rapport & 553 & 50.5 & 52.5 & .64 & 517 & $54(44-64)$ & .46 \\
\hline Patient preference for particular specialist & 553 & 39.9 & 42.2 & .59 & 517 & $47(36-57)$ & .20 \\
\hline Patient convenience & 551 & 17.4 & 32.0 & $<.01$ & 515 & $26(17-36)$ & .06 \\
\hline Office location & 551 & 7.1 & 12.4 & .04 & 515 & $12(6-22)$ & .14 \\
\hline
\end{tabular}




\begin{tabular}{|c|c|c|c|c|c|c|}
\hline \multirow[b]{2}{*}{ Factor } & \multicolumn{4}{|c|}{ Unadjusted Percent } & \multicolumn{2}{|c|}{ Adjusted Percent* $(95 \% \mathrm{Cl}$} \\
\hline & No. & Male & Female & $P$ Value & Female & $P$ Value \\
\hline \multicolumn{7}{|l|}{ Specialist characteristics } \\
\hline Medical skill & 545 & 83.6 & 87.2 & .23 & $90(83-94)$ & .09 \\
\hline Board certification & 549 & 30.2 & 37.1 & .09 & $36(27-47)$ & .24 \\
\hline \multicolumn{7}{|l|}{ Practice characteristics } \\
\hline Appointment timeliness & 549 & 57.0 & 53.9 & .47 & $51(41-61)$ & .26 \\
\hline Insurance coverage & 550 & 43.6 & 55.0 & $<.01$ & $60(50-70)$ & $<.01$ \\
\hline Hospital affiliation & 551 & 13.9 & 13.4 & .85 & $16(9-26)$ & .59 \\
\hline \multicolumn{7}{|l|}{ Primary care physician-specialist } \\
\hline \multicolumn{7}{|l|}{ Interaction } \\
\hline $\begin{array}{l}\text { Primary care physician previous experience with } \\
\text { specialist }\end{array}$ & 552 & 59.7 & 58.8 & .84 & $62(51-71)$ & .73 \\
\hline Specialist returns patient to primary care physician & 550 & 59.0 & 44.2 & $<.01$ & $46(36-56)$ & .01 \\
\hline Quality of communication & 552 & 52.9 & 52.2 & .87 & $48(38-58)$ & .31 \\
\hline Primary care physician relationship with specialist & 552 & 35.1 & 36.5 & .74 & $35(26-45)$ & .95 \\
\hline Attitudes of colleagues toward the specialist & 553 & 12.4 & 16.3 & .19 & $15(9-24)$ & .45 \\
\hline \multicolumn{7}{|l|}{ Patient-specialist interaction } \\
\hline Likelihood of good patient-physician rapport & 553 & 52.5 & 50.3 & .61 & $54(44-63)$ & .82 \\
\hline Patient preference for particular specialist & 553 & 42.1 & 39.8 & .59 & $39(30-49)$ & .52 \\
\hline Patient convenience & 551 & 25.9 & 21.9 & .28 & $19(13-28)$ & .11 \\
\hline Office location & 551 & 10.1 & 8.9 & .63 & $8(4-14)$ & .33 \\
\hline
\end{tabular}

completely clear. Previous experience with the specialist was of major importance to the vast majority of respondents. If previous experience is limited, other factors such as board certification might be considered. Board certification status was considered to be of major importance to only one third of respondents, however. Similarly, in a previous study ${ }^{8}$ board certification was not associated with increased receipt of referrals by non-primary care physicians. Additionally, the site of a specialist's medical school education or fellowship training did not appear to be proxies for medical skill.

In general, the results of our study support those found in previous work limited in geographic representation ${ }^{14,16,17}$ but go further in exploring the role of physician race and sex. Unlike other studies, blacks and women (whose representation among US medical students now approaches $50 \%)^{18}$ were well represented in our study population. Black and white physicians might differ in the ethnicity and socioeconomic status of their patients, in patient ratings of the physician's participatory decision-making style, and in patient-centered communication, particularly for race-discordant patient-physician relationships. ${ }^{19,22,-24,31,32}$ Our study assessed whether differences might also be seen in one aspect of the referral process. Although the importance of many factors in the referral decision did not vary sig- nificantly by race and sex of the physician, there were some important exceptions. Compared with white physicians, a greater proportion of black physicians rated patient convenience to be of major importance in the referral decision, although this finding was of borderline significance in multivariate analysis. One potential explanation is that caring more often for socioeconomically disadvantaged and vulnerable patients, many of whom have financial and transportation barriers to care, might lead black physicians to consider patient convenience more highly than white physicians in their referral priorities. As patients sometimes do not keep appointments with specialists to whom they have been referred, ${ }^{33,34}$ it is possible that greater discussion with patients, particularly in vulnerable populations, about potential barriers to receiving specialty care might improve referral completion and enhance patient care.

Medical skill of the specialist was the most highly regarded factor by both black and white physicians; however, black and white physicians differed in their views of board-certification status as a major factor in choice of specialists. Perhaps black physicians consider factors other than board certification to be more important in the referral process, such as cultural sensitivity, flexibility in financial arrangements for patients, or other indicators of quality, such as the specialist's pro- 
cedure volume or experience with certain patient populations. It is also possible that black physicians might be more likely to practice in locations with limited choices of specialists available to care for their patients; therefore, availability might be a more important concern than board-certification status.

We found that female physicians were more likely to rate insurance coverage to be of major importance in their referral decisions for patients and less likely than male physicians to rate specialist return of patient to be of major importance. Studies of the practices of female physicians indicate that they see more patients with complex social problems, ${ }^{35}$ are rated by patients as being more participatory in their decision-making styles, ${ }^{19}$ and engage in more communication that can be considered patient centered. ${ }^{26}$ Our findings related to the importance of insurance coverage are consistent with the patient-centered and socially conscious practices of women physicians described in previous work. Another potential explanation for this finding is that women physicians might be more sensitive to the impact of health insurance on quality and costs of health care for patients because they spend more time on family and child-rearing activities their male colleagues, ${ }^{36}$ and because women generally make more health care decisions for their family members. ${ }^{37}$

The study has a number of limitations. First, the response rate was $59 \%$. This rate, however, exceeds the average response rate of $52 \%$ of published, largesample, mailed physician surveys. ${ }^{38}$ Respondents and nonrespondents were similar in terms of sex, specialty, and geographic region, but respondents were more likely than nonrespondents to be white. Second, while the list of items was largely derived from past studies, we may not have included factors potentially of greater importance to physicians. More in-depth interviews or qualitative studies with physicians might help identify other important factors. Third, while we attempted to control for practice type in the multivariate analyses, it is possible that this variable does not capture adequately the heterogeneity of practice environments within each practice type. For example, a primary care physician in private practice may find the choice of specialists limited in different degrees by the availability of specialists in an area and the restrictions placed by various payers on the specialists to whom patients can be referred. Fourth, the importance of the factors in the referral decision is based on physician report and may not reflect actual physician behavior.

More than 20 years ago, Ludke ${ }^{16}$ wrote that "programs for accepting patient referrals, diagnosing and/or treating those patients and returning the patients to the referring physicians should be structured and operated in such a way that recognize the factors that a consultant's potential clientele consider important in the referral process." Likewise, our findings emphasize the current importance of understanding the expectations that referring physicians have of specialists. Given the considerable problems maintaining continuity of patient care, for example, the great importance attached to physician communication and return of the patient to the primary care physician for further care is notable. Understanding the factors that primary care physicians consider important in the referral process and how these factors vary by physician characteristics, including race and sex, may be useful in developing and tailoring educational or organizational interventions to improve the referral process. Similarly, the possibility that primary care physicians' demographic and practice characteristics might affect their views on specialist choice may provide additional insight on our changing physician workforce.

Both primary care physicians and specialists need to be aware of the factors and systematic biases that can enter into decision making regarding referrals in primary care. Use of patient-centered approaches in the referral process, as well as increasing diversity in the physician workforce, is consistent with the Institute of Medicine recommendations on quality of care..$^{39,40}$ This study sheds light on how women, who have increased their numbers in medicine and primary care, and blacks may differ in their approach to recommending specialists for their patients. Further efforts to understand how diversity affects medical decision making and quality of care, particularly for vulnerable patient populations, is needed. Future research also might address how physicians adapt to changes in traditional referral relationships, how physicians obtain information on specialists for possible referral, physician educational and administrative needs with regard to the referral process, and the role of physician race and sex in the referral process.

To read or post commentaries in response to this article, see it online at http://www.annfammed.org/cgi/content/full/2/3/245.

Key words: Referrals, primary care physicians; specialists; physician workforce diversity; race disparities; ethnic disparities

Submitted January 6, 2003; submitted, revised, April 29, 2003; accepted June 9, 2003.

Funding support: Dr. Kinchen was a fellow in the Robert Wood Johnson Clinical Scholars Program during the time this work was conducted. Dr. Powe was supported by grant number K24DK02643 from the National Institute of Diabetes and Digestive and Kidney Diseases, Bethesda, Md. Dr. Cooper was supported by a grant from the Commonwealth Fund.

Disclaimer: The views presented here are those of the authors and not necessarily those of the Commonwealth Fund, its directors, officers, or staff. 


\section{References}

1. Engel W, Freund DA, Stein JS, Fletcher RH. The treatment of patients with asthma by specialists and generalists. Med Care. $1989 ; 27: 306-314$

2. Cummins RO, Smith RW, Inui TS. Communication failure in primary care. Failure of consultants to provide follow-up information. JAMA. 1980;243:1650-1652.

3. Avorn J, Bohn RL, Levy E, et al. Nephrologist care and mortality in patients with chronic renal insufficiency. Arch Intern Med. 2002;162 2002-2006.

4. Nutting PA, Franks $P$, Clancy CM. Referral and consultation in primary care: do we understand what we're doing? J Fam Pract. $1992 ; 35: 21-23$

5. Glenn JK, Lawler FH, Hoerl MS. Physician referrals in a competitive environment. An estimate of the economic impact of a referral. JAMA. 1987;258:1920-1923.

6. Frieri M, Therattil J, Dellavecchia D, Rockitter S, Pettit J, Zitt M. A preliminary retrospective treatment and pharmacoeconomic analysis of asthma care provided by allergists, immunologists, and primary care physicians in a teaching hospital. J Asthma. 2002;39:405-412.

7. Franks $P$, Clancy CM. Referrals of adult patients from primary care: demographic disparities and their relationship to HMO insurance. J Fam Pract. 1997;45:47-53

8. Gonzalez ML, Rizzo JA. Physician referrals and the medical market place. Med Care. 1991;29:1017-1027.

9. Grembowski DE, Cook K, Patrick DL, Roussel AE. Managed care and physician referral. Med Care Res Rev. 1998;55:3-31.

10. Mack JM. Managed care relationships from the physician's perspective. Top Health Care Financ. 1993;20:38-52.

11. Roulidis ZC, Schulman KA. Physician communication in managed care organizations: opinions of primary care physicians. J Fam Pract. 1994;39:446-451.

12. Shortell SM, Daniels RS. Referral relationships between internists and psychiatrists in fee-for-service practice: an empirical examination. Med Care. 1974;22:229-240

13. Shortell SM. Patterns of referral among internists in private practice: a social exchange model. J Health Soc Behav. 1973;14:335-348.

14. Brock C. Consultation and referral patterns of family physicians. J Fam Pract. 1977;4:1129-1134.

15. Ludke RL, Levitz GS. Referring physicians: the forgotten market. Health Care Manage Rev. 1983;8:13-22.

16. Ludke RL. An examination of the factors that influence patient referral decisions. Med Care. 1982;20:782-796.

17. Javalgi $R$, Joseph WB, Gombeski WR Jr, Lester JA. How physicians make referrals. J Health Care Mark.1993;12:6-17.

18. Salsberg ES and Forte GJ. Trends in the physician workforce, 19802000. Health Aff (Millwood). 2002;21:165-172.

19. Cooper-Patrick L, Gallo JJ, Gonzalez JJ, et al. Race, gender, and partnership in the patient-physician relationship. JAMA. 1999;282: 583-589.

20. Weisse CS, Sorum PC, Sanders KN, Syat BL. Do gender and race affect decisions about pain management? J Gen Intern Med. 2001;16:211-217.

21. Keith SN. Role of minority providers in caring for the underserved. J Health Care Poor Underserved. 1990;1:90-95.
22. Komaromy M, Grumbach K, Frake M, et al. The role of black and Hispanic physicians in providing health care for underserved populations. N Engl J Med. 1996;1305-1310.

23. Moy E, Bartman BA. Physician race and care of minority and medically indigent patients. JAMA. 1995;273:1515-1520

24. Xu G, Fields K, Lain C, Veloski JJ, Barzansky B, Martini CJ. The relationship between the race/ethnicity of generalist physicians and their care for underserved populations. Am J Public Health. 1997;87:817822.

25. Hargraves JL, Stoddard JJ, Trude S. Minority physicians' experiences obtaining referrals to specialists and hospital admissions. MedGenMed 2001;3:10.

26. Roter DL, Hall JA, Aoki YA. Physician gender effects in medical communication; a meta-analytic review. JAMA. 2002;288:756-764.

27. Byrd WM, Clayton LA, Kinchen K, et al. African-American physicians' views on health reform: results of a survey. J Natl Med Assoc. 1994;86:191-199.

28. Lanier DC, Clancy CM. The changing interface of primary and specialty care. J Fam Pract. 1996;42:303-305.

29. Ghandi TK, Sittig DF, Franklin M, Sussman AJ, Fairchild DG, Bates DW. Communication breakdown in the outpatient referral process. I Gen Intern Med. 2000:15:626-631.

30. Zhang J, Yu KF. What's the relative risk? A method of correcting the odds ratio in cohort studies of common outcomes. JAMA. 1998;280:1690-1691.

31. Kaplan SH, Gandek B, Greenfield S, Rogers W, Ware JE. Patient and visit characteristics related to physicians' participatory decisionmaking style. Results from the Medical Outcomes Study. Med Care. 1995:33:1176-1187.

32. Cooper LA, Roter DL, Johnson RL, Ford DE, Steinwachs DM, Powe NR. Patient-centered communication, ratings of care, and concordance of patient and physicians race. Ann Intern Med. 2003;139:907915.

33. Hobson SK. Making referrals-there is more to it than you think. Pediatr Nurs. 1998;24:160-161.

34. Jones VF, Sisson B, Kurbasic M, Thomas A, Badgett JT. Subspecialist referrals in an academic, pediatric setting: rationale, rates, and compliance. Am J Manag Care. 1997;3:1307-1311.

35. McMurray JE, Linzer M, Konrad TR, Douglas J, Shugerman R, Nelson $\mathrm{K}$. The work lives of women physicians results from the physician work life study. The SGIM Career Satisfaction Study Group. J Gen Intern Med. 2000; 15:372-380.

36. Frank E, Harvey L, Elon L. Family responsibilities and domestic activities of US women physicians. Arch Fam Med. 2000;9:134-140.

37. Collins KS, Schoen C, Joseph S, Duchon L, Simantov E, Yellowitz M Health Concerns Across a Woman's Lifespan: The Commonwealth Fund 1998 Survey of Women's Health. New York, NY: The Commonwealth Fund; 1999

38. Cummings SM, Savitz LA, Konrad TR. Reported response rates to mailed physician questionnaires. Health Serv Res. 2001;35:1347-1355.

39. Institute of Medicine. Crossing the Quality Chasm: A New Health System for the 21st Century. Washington, DC: National Academies Press; 2001.

40. Institute of Medicine. Unequal Treatment Confronting Racial and Ethnic Disparities in Health Care. Washington, DC: National Academies Press; 2002 